\title{
Fixed drug eruption induced by Moringa oleifera leaf extracts - A case report
}

\author{
Fatai Olatunde Olanrewaju, Olaniyi Onayemi, Olayinka Abimbola Olasode, \\ Muphy Mufutau Oripelaye
}

Department of Dermatology, Obafemi Awolowo University Teaching Hospitals Complex, Ile-ife, Osun state, Nigeria

Corresponding author: Dr. Fatai Olatunde Olanrewaju, E-mail: docjufat@yahoo.com

\begin{abstract}
Fixed drug eruption (FDE) is a commonly encounter cutaneous drug reaction at the dermatology clinics. The diagnosis is made when a characteristic lesion occurred repeatedly at the same site following re-exposure to the precipitating agent. We are presenting Moringa oleifera as a cause of FDE in a 55 year old man making the plant part of the growing list of implicating agents causing FDE. The mechanism by which it causes the lesion may not be completely understood but may probably be due to high sulphur content in the leaf extracts. The sulphur may serve as hapten and activate CD $8+$ effector/memory T- cell leading to generation of proinflammatory cytokines such as interferon-gamma which causes tissue damage.
\end{abstract}

Key words: Moringa oleifera; Fixed drug eruption; Sulphur

\section{INTRODUCTION}

The natural origin and supposed safety of alternative medicine in form of herbal medication have made them to gain wide acceptability throughout the world. Moringa oleifera has been of particular interest as evidence by its increasing cultivation and use especially in Nigeria in the past one decade. Despite increased use, not much has been said about the adverse reactions especially cutaneous side effects following consumption of its different parts- leaves, pods, beans, back and roots. We are reporting a rare case of fixed drug eruption (FDE) following consumption of aqueous leaf extract of Moringa oleifera. We suggest that attending dermatologist be aware and have high index of suspicion of Moringa oleifera as a cause of FDE while making a diagnosis most especially in those that developed FDE while taken herbal preparations.

Moringa oleifera belong to the genus Moringa and Moringaceae family and is the commonest of the thirteen species [1]. The plant is native to northern
India but has become naturalized and widely cultivated in West Africa [2,3].

M. oleifera is known by many indigenous names such as horseradish tree, benzolive, drumstick tree, kelor, merango, mlonge, mulangay,saijhan and sajna [4]. In Nigeria, the plant is recognized by the Hausa as zogale, Fulani as kabije, Yoruba as Igi-iyanu and Igbo as Okweoyibo [5]. Many therapeutic effects like antibiotic, anticancer, antioxidant, antihypertensive has been attributed to this wonder plant $[5,6]$. The documented dermatological uses include improvement in wound healing, reduce wrinkle, improves acne vulgaris and psoriasis, the seed oil as an emollients, hair conditioner and antifungal properties [6]. The plant has been demonstrated to have inhibitory effect on Trichophyton rubrum and Trichophyton mentagrophytes $[7,8]$.

Moringa oleifera leaf extracts contain significant amount of important nutrient such as carbohydrates, lipids and proteins in form of essential amino acids, vitamins $\mathrm{A}, \mathrm{B}$ and $\mathrm{C}$, minerals like potassium, calcium, iron, zinc, phosphorus and sulphur. The

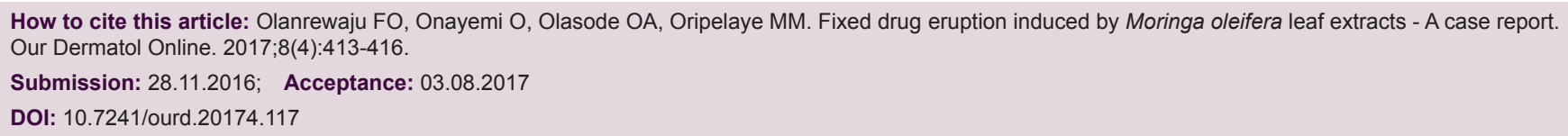


sulphur content per $100 \mathrm{~g}$ of leaves can be as high as $137 \mathrm{mg}$ and $870 \mathrm{mg}$ for fresh and dried leaves respectively $[9,10]$.

\section{CASE REPORT}

A 55 year old Nigerian man presented at the dermatology clinic complaining of recurrent dark spots on his trunk, arm, forearm and thigh for 1 year (Figs. 1-4). The dark spots usually reappeared on the same sites and occasionally new ones appeared at different sites. They usually began with itching, erythema and sometimes vesicles at the center of the lesions. It eventually subsided within 2-3 weeks to leave annular hyperpigmented patches. He has had several episodes in the past one year prior to presentation with worsening of symptoms following each repeated

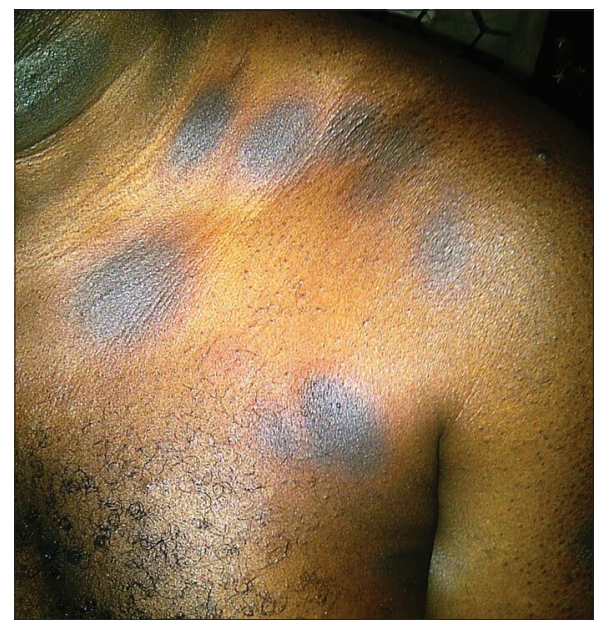

Figure 1: Hyperpigmented fixed drug eruption with erythematous edge on the left shoulder region.

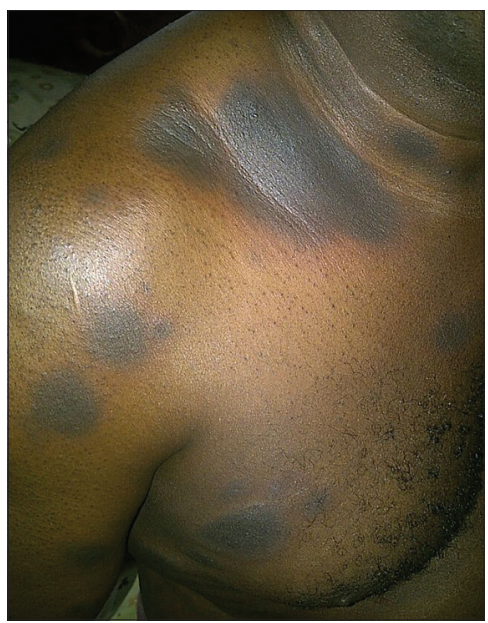

Figure 2: Hyperpigmented fixed drug eruption patch on the right shoulder region. episodes of which no attributable etiology was found by the patient.

Skin examination revealed multiple annular hyperpigmented (Figs. 1 and 2), edematous patches (Fig. 4) and plaques $2-4 \mathrm{~cm}$ in diameter with erythematous edges (Fig. 1), on the chest, arm, forearm and thigh. The buccal mucosal were spared. The provisional diagnosis of fixed drug eruption was made at the first clinic visit but the offending agent could not be ascertain having denied oral intake of any common medication known to induced FDE. The patient however claimed to first noticed the lesions in the past one year when he started taken water based leaf extract of Moringa oleifera as blood detoxifying agent. He was subsequently counseled to meticulously lookout for these cutaneous lesions when taking any medications. The patient presented two weeks later with reappearance of similar lesions and

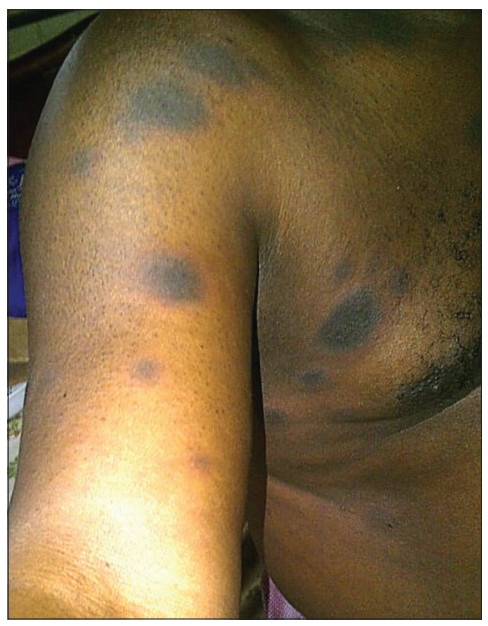

Figure 3: Hyperpigmented fixed drug eruption on the right arm.

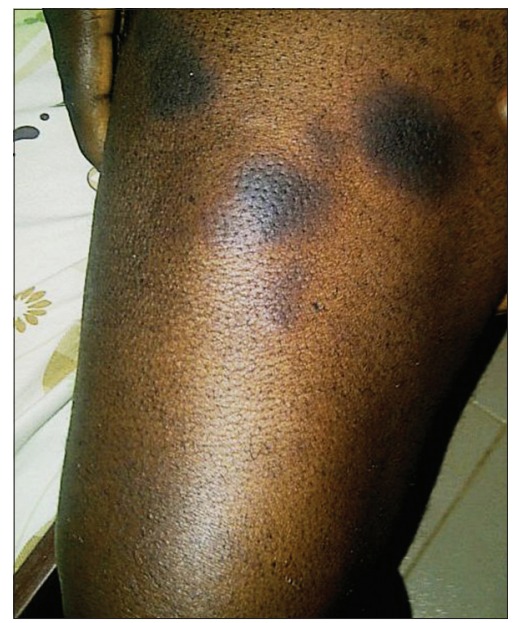

Figure 4: Urticaric and hyperpigmented fixed drug eruption on the right thigh. 
deeper hyperpigmentation of the pre-existing patches following oral consumption of freshly prepared leaf extract of Moringa oleifera. This confirmed our initial diagnosis of fixed drug eruption and the implicating agent. There was no significant finding on systemic review and no constitutional symptoms such as fever, malaise, nausea and vomiting. The complete blood count and other biochemical parameters were all within normal physiological range. The diagnosis of FDE is usually made clinically, other useful tests required in establishing diagnosis of FDE include patch test on affected skin, drug challenge and biopsy of lesional skin. Patient was counseled to stop consumption of Moringa oleifera and was treated with antihistamine and topical steroid with resolution of symptoms but the post-inflammatory hyperpigmentation remained. He has been on follow up with no appearance of the lesion in the past two years since he stopped consumption of Moringa oleifera.

\section{DISCUSSION}

Fixed drug eruption is the term used to describe the appearance of skin lesions on precisely the same site(s) each time the incriminating drug is administered. Brocq first coined the term fixed drug eruption in 1894 but the entity was earlier described in 1889 by Bourns when he noticed the characteristic skin reactions to antipyrine [11].

FDE has been reported by many authors to be caused by increasing list of different agents including antibiotics, anticonvulsants, analgesics and herbal medications. The plant leaf extract have high sulphur content which probably serve as hapten to induce FDE $[9,10]$. The clinical diagnosis of fixed drug eruption is made by taking a careful history to elicit the fact that a drug, over-the-counter medications has been taken and when a characteristic adverse cutaneous drug reaction appear at the same site(s) upon repeated exposure to the offending agent. Among the commonest agents reported to cause FDE are sulphonamides and nonsteroidal anti-inflammatory drugs (NSAID) [12]. The sites and appearances can be different and any part of the skin or mucous membrane can be affected. The precipitating agent or drug can have predilections for specific sites [13]. Tetracycline tends to cause FDE on the glans penis, sulphonamides cause lesions on any part of the body and NSAID such as aspirin usually affects the trunk and limbs [12]. The lesion of FDE may present as targetoid, bullous/vesicular, hyperpigmented, nonpigmented or urticaric, migrating, linear, eczematous or generalized.

The mechanism by which medications cause FDE is not completely understood, however the condition is thought to be due to delayed (type IV) hypersensitivity reactions [14]. Excessive activation of intraepidermal CD8 ${ }^{+}$effector/memory T-cells which are resident in FDE lesions are said to be very important and sufficient enough in the pathogenesis and reactivation of lesions. The CD $8+$ T-cells propagate tissue damage by releasing pro-inflammatory cytokines such as interferon-gamma and tumor necrosis factoralpha [15]. To confirm diagnosis re-challenge test can be undertaking cautiously in order to avoid extensive bullous lesion such as Steven-Johnson syndrome and toxic epidermal necrolysis.

\section{CONCLUSION}

Moringa oleifera consumption has increased in recent time for different reasons. FDE is a rare adverse cutaneous side effect of the plant and physicians need to be aware of this side effect. We report a rare case of FDE following consumption of aqueous extract of Moringa oleifera leaves. We recommend that physicians should be on the lookout for this side effect when taking history from patients with FDE.

\section{Abreviations}

FDE: Fixed Drug Eruption; NSAID: Non-Steroidal Anti-inflammatory Drugs.

\section{REFERENCES}

1. Rita P, Veena S, Veena S. A review on Horse Radish tree (Moringa oleifera): A multipurpose tree with High economic and commercial importance. Asian Journal of Biotechnology. 2011; 3: 317-328.

2. Rockwood JL, Anderson BG, Casamatta DA. Potential uses of Moringa oleifera and an examination of antibiotic efficacy conferred by M. oleifera seed and leave extracts using crude extraction technique available to underserved indigenous populations. Int J Phytother Res. 2013;2:61-71.

3. Sachan A. Meena AK, Kaur R, Pal B, Singh B. Moringa oleifera: Rev J Pharm Res. 2010;3:840-2.

4. Jed WF. Moringa oleifera: A review of the medical evidence of its nutritional, therapeutic and prophylactic properties. Tree Life J. 2005;1:5.

5. Dahiru D, Onubiyi JA, Umaru HA. Phytochemical screening and antiulcerogenic effect of Moringa oleifera aqueous leaf extract. African J Trad Comp Alternat Med. 2006;3:70-5.

6. Jung IL. Soluble extract from Moringa oleifera leaves with a new anticancer activity. PLoS One. 2014;9:e95492.

7. Marcu MG. Miracle tree. KOS publications, USA. 2015; ISBN-13.

8. Maria ON, Okafor JI. Preliminary studies of the antifungal activities 


\section{www.odermatol.com}

of some medicinal plants against Basidiobolus and some other pathogenic fungi. Mycoses. 1995;38:191-5.

9. Mbailao M, Mianpereum T, Ngakou A. Proximal and elemental composition of moringa oleifera leave from three regions of chad. J Food Resour Scien. 2014;3:12-20.

10. Dhakar RC, Maurya SD, Pooniya BK, Bairwa N, Gupta M, Moringa $\mathrm{S}$. The herbal gold to combat malnutrition. Chron Young Sci. 2011;2:119-25

11. Bourns D. Unusual effects of antipyrine. BMJ. 1889;2:818-20.

12. Shukla P, Prabhudesai R. Fixed drug eruption to fluconazole. Indian J Dermatol (serial online). 2005;50:236-7.

13. Breathnach SM. Drug reaction. In: RA Champion, JI Burton,
DA Burns, SM Breathnach, eds. $6^{\text {th }}$ ed. Vol 4. Blackwell Science, 1998: 3378-3379.

14. Lareb. Nederlands Bijwerkingen centrum November 2007.

15. Shiohara T. Fixed drug eruption: Pathogenesis and diagnostic tests. Curr Opin Allergy Clin Immunol. 2009;9:316-21.

Copyright by Fatai Olatunde Olanrewaju, et al. This is an open access article distributed under the terms of the Creative Commons Attribution License, which permits unrestricted use, distribution, and reproduction in any medium, provided the original author and source are credited.

Source of Support: Nil, Conflict of Interest: None declared. 